\title{
Education and Cultivation of Undergraduates' Innovative Ability Based on Philosophical Thinking
}

\author{
Chunying Zhang $^{1}$, Leilei Zhao ${ }^{2, *}$ \\ ${ }^{1}$ School of Marxism, Shandong University of Technology, Zibo, China \\ ${ }^{2}$ School of Transportation and Vehicle Engineering, Shandong University of Technology, Zibo, China
}

Email address:

dyn_keylab@163.com (Chunying Zhang), zhaoleilei611571@163.com (Leilei Zhao)

*Corresponding author

To cite this article:

Chunying Zhang, Leilei Zhao. Education and Cultivation of Undergraduates' Innovative Ability Based on Philosophical Thinking. Science Journal of Education. Vol. 9, No. 1, 2021, pp. 1-5. doi: 10.11648/j.sjedu.20210901.11

Received: January 4, 2021; Accepted: January 21, 2021; Published: January 28, 2021

\begin{abstract}
At present, the teaching mode of professional courses is not compatible with the cultivation of undergraduates' innovative ability. This is an important factor that restricts the cultivation of undergraduates' innovative ability. To effectively enhance undergraduates' innovative ability, this paper proposed a method of integrating philosophical thinking into professional courses teaching. Firstly, the dialectical relationship between the philosophical thinking and the cultivation of innovative ability was investigated. Then, the present situation of teaching and learning of professional courses in universities was analyzed. Moreover, the specific suggestions for the teaching reform of professional courses were given. Lastly, combining with a case study, this paper makes an analysis of how to improve undergraduates' innovative ability by cultivating their philosophical thinking. The results show that the teaching effects and teaching quality are improved. Some useful and important conclusions can be summed up as: Philosophical thinking and innovative ability are dialectically unified. Combining philosophical thinking with professional teaching can cultivate undergraduates' ability to apply philosophical methodology and effectively improve their innovative ability. Colleges and universities should actively promote the teaching method of combining philosophical thinking with professional course teaching, and give full play to the exemplary role of excellent courses based on this teaching method.
\end{abstract}

Keywords: Philosophical Thinking, Education, Curriculum Studies, Undergraduates, Innovative Ability

\section{Introduction}

Universities are the gathering places of undergraduates, shouldering the mission of training innovative talents [1]. At present, the common problem in the education of engineering undergraduates in many countries, especially in China, is the low innovative ability and lack of innovative philosophical thinking $[2,3]$.

Many undergraduates lack the ability to analyze and solve problems in the graduation design stage, although they have good exam results [4]. After graduation, some students choose to take postgraduate entrance exams and want to continue their studies. However, many of them are still eliminated in the interview process of innovative competence even though they rank high in the first test results. Some others choose to take up an occupation. With the intensification of competition among enterprises, higher requirements for the innovative ability of the introduced university graduates $[5,6]$. When recruiting university graduates, many enterprises have added test links of innovative thinking. However, many excellent graduates can't successfully pass the inspection, so they can't get the job they want. Even if some graduates pass this link by chance, it is very difficult for them to adapt to the requirements of innovative design and research jobs. For example, eleven graduates recruited by Binzhou PSL Pencil Co., Ltd. were excellent in their studies during the university period, but after the probation period, only three graduates were found to be able to meet the needs of product design, while the others were only suitable for ordinary operation. The main reason for this phenomenon is that university teachers do not pay enough attention to the cultivation of undergraduates' innovative ability in the teaching process of professional courses. This makes it difficult for many graduates to adapt to 
the needs of enterprises and society.

With more and more negative evaluations about undergraduates' innovative ability from enterprises and society, university teachers have gradually realized that they must attach importance to the cultivation of undergraduates' innovative ability [7, 8]. Many scholars have studied the cultivation of undergraduates' innovative ability, realized the importance of philosophical thinking to the cultivation, and given valuable countermeasures [9-11]. However, most of these studies are from a macro perspective and the philosophical thinking process of the innovation is not discussed. They did not integrate philosophical thinking into the professional courses teaching.

To effectively enhance undergraduates' innovative ability, this paper proposed a method of integrating philosophical thinking into professional courses teaching. The specific suggestions for the teaching reform of professional courses were given. With a case study, how to improve undergraduates innovative ability by cultivating their philosophical thinking was illustrated in details.

\section{The Relation Between Philosophical Thinking and Innovative Ability}

\subsection{Philosophical Thinking is the Necessary Condition of Innovative Ability}

Philosophical thinking is the necessary conditions of innovative ability, but not the sufficient condition. This is why we have studied philosophy for many years, and we also feel that the contents of philosophy principle seem to be very clear, but we still lack the ability of innovation and theoretical innovation in subject research. People with innovative ability have a good philosophical foundation and can use innovative philosophical thinking to create important theories.

\subsection{Innovation Ability is the Actual End-result of Philosophical Thinking}

Applying philosophical thinking helps to realize great innovation. If we do not use philosophical thinking to analyze and solve problems, it will be difficult to make major breakthroughs in theory and methods. Real life, work, and scientific research require us to put philosophical thinking into practice. Innovation ability is just the actual end-result of philosophical thinking. Therefore, in learning philosophy, we must attach importance to philosophical thinking, grasp the process and methodology of innovative philosophical thinking, and cultivate innovative thinking ability.

\subsection{Dialectical Unity of Innovation Ability and Philosophical Thinking}

Philosophical thinking and innovative ability are dialectically unified. They are complementary, interdependent, and inseparable. On the one hand, innovative ability can not be separated from philosophical thinking. If we abandon philosophical thinking, innovative ability can not be improved.
On the other hand, philosophical thinking can not be separated from innovation ability. As everyone knows, development is the eternal theme of human society. Philosophical thinking can't continue to develop and can't form new philosophical theory achievements, if it is separated from the innovative activities of innovative people.

From the above analysis, it can be seen that it is not enough to unilaterally strengthen the knowledge of philosophy or memory for the cultivation of students' innovative ability. Teachers should also let students master how to use philosophical thinking to innovate.

\section{Analysis of Current Situation of Teaching and Learning in University}

University teaching involves a variety of courses. Among all the courses, professional courses have a direct and important impact on the further development of students, including postgraduate entrance examination, further study, work, and so on. Therefore, this study mainly focuses on the analysis of the current situation of teaching and learning of professional courses in universities. Philosophy course not only cultivates students' outlook on life, but also helps them to learn professional courses. Thus, the current situation of philosophy course is briefly analyzed at first.

\subsection{The Current Situation of Philosophy Teaching}

At present, many colleges and universities have realized the role of philosophical thinking in the cultivation of students. Therefore, the philosophy courses offered are full of branches, the teaching staff is relatively strong, and the teachers are relatively skilled in the teaching content $[12,13]$. However, the following shortcomings still exist:

(1) Teachers of philosophy courses can not grasp all kinds of professional courses that students will learn, so it is difficult to link philosophical thinking with specialized courses. (2) Teachers mostly use the way of final closed-paper examination to examine students' cognition of philosophical contents. As a result, students can only memorize by rote and can not grasp the methodology of philosophy well.

\subsection{Current Situation of Professional Courses Teaching}

At present, most professional courses are taught by modern teaching methods, and professional knowledge of professional teachers is also very rich [14]. However, there are still some shortcomings:

When explaining professional knowledge, teachers lack the analysis of philosophical thinking process and the ability to train students to innovate correctly. The combination of teaching content and philosophical system is little. Many teachers only let students memorize professional knowledge. Students only know what they know and don't know why, which affects their enthusiasm and interest in learning professional courses. Teacher lack the links to train students' ability of analyzing and solving practical problems. 
Professional teachers to cultivate the innovation ability of awareness is not enough, and they do not know what is the role of philosophy for the cultivation of innovative ability. Teachers often pay attention to explaining the knowledge points of the syllabus, but often neglect the extension of the important knowledge points and the cultivation of students' innovative ability. Teachers are lack of discovering the training points of innovative ability in teaching contents. For the experiment in the course, the teacher only lets the students master the experiment process and method, neglecting the ability cultivation of data analysis and processing.

From the above analysis, it can be seen that the important shortcoming of the current university teaching is that the teaching of philosophy is out of touch with the teaching of professional courses. Thus, philosophical thinking can not play a good role in students' learning professional courses. This leads to the ineffective cultivation of innovative ability. In other words, teachers can not integrate professional teaching and philosophy education well. In the process of classroom teaching, they only pay attention to the teaching of concepts, principles, and operation steps, but neglect the cultivation of professional quality and innovation consciousness. Therefore, one of the important reasons for the ineffective exertion of philosophical thinking in the teaching of specialized courses is the misplacement of teachers' ideological cognition and their poor comprehensive quality.

\subsection{Current Situation of Professional Courses Learning}

\section{(1) Lack of innovation ability improvement process}

Less homework is done independently in professional courses. Many students plagiarize homework. This will inevitably result in many students losing the opportunity to cultivate the ability to think independently, to analyze, and to innovate.

(2) Only pay attention to professional knowledge and memory

Nowadays, when college students study professional courses, as long as they feel that the knowledge taught by the teachers is remembered, they think they have mastered the professional courses they have learned. They do not have a deep understanding of how the theories and methods taught by the teachers are thinking out, nor have they learned to find solutions to problems, nor have they used philosophical thinking to establish new theoretical methods.

\section{(3) Lack of initiative in learning}

Some students lack interest in professional courses. Most of the students are in a passive learning state, while some are active learners. Few students can achieve the state of interest in learning. The main reason is that the purpose of learning is not clear. Many students are not for the future to find a good job, nor for scientific research, just to pass the exam. Many students still use the way of language learning in primary and secondary schools, recite and strengthen memory before examinations to cope with examinations. In this way, although they can get a good result, but they have not learned to study independently and have not developed the ability of self-study and innovation.

\section{Suggestions on Teaching Reform and Case Study}

\subsection{Suggestions on Teaching Reform}

Teachers should fully tap the internal relationship between professional knowledge and philosophical thinking, find the combination of professional knowledge and philosophical thinking, so that students are influenced and baptized by philosophical thinking in the process of learning professional courses. Teachers should explain the thinking process of the birth of the idea and method of the problem, that is, what the method is based on, and guide students to use their brains to think and find or create new ways to solve the problem. Teachers should not only give students a "key" to open problems, but also let them learn how to find the "key" to open problems according to specific practical problems, that is, to find solutions to problems. They should also teach students how to build new theories and methods according to the problems they encounter. Professional teaching in colleges and universities should aim at cultivating students' innovative ability, reform teaching methods, let students truly learn to use philosophical thinking to innovate, and cultivate students' theoretical analysis ability and ability to solve practical problems.

\subsection{Case Study}

As a core professional course of Vehicle Engineering, «Automobile Theory» plays an important role in the course system of Vehicle Engineering [15]. Among them, the fifth chapter, "Vehicle handling and stability" is the core chapter of the course. Taking this chapter as an example, this paper analyses the theory and method of creating vehicle handling dynamics model and response analysis by philosophical thinking.

\section{(1) Teaching of model hypothesis conditions}

When describing the dynamics model of vehicle handling, the differential equation of motion of the model can not be given directly. It is necessary to explain the hypothesis of the model by using the "contradictory philosophical principle". From the content point of view, it is not difficult for students to understand the principle of the relationship between the main contradiction and the secondary contradiction, but it is important and complex for them to learn how to use this principle to handle the dialectical relationship between the two.

Automobile is a very complex coupling system, and it is impossible for us to build the same theoretical model as in reality. In order to facilitate theoretical analysis, it is necessary to simplify the car as a system. The purpose of establishing the model is to analyze the basic principle of vehicle handling and stability, so it is not that the more degrees of freedom the model has, the better is. If the model can reflect the basic response characteristics of vehicle handling and stability, it will meet the requirements. Therefore, two degrees of freedom of the model are considered in the textbook, including yaw degree of freedom and lateral degree of freedom. For the most 
basic stability of vehicles, the steering system, suspension system and geometric shape of vehicles are secondary, so we ignore their influence. Vehicle tyres are directly related to the safety of vehicles, so the performance of tyres must be considered.

Through the above explanations, students can understand the origin of the hypothetical conditions for modeling, and flexibly use the "contradictory philosophical principles" to make the conditions for model building. For example, to analyze the influence of suspension characteristics on handling and stability, the suspension system becomes the main factor to be considered in modeling, so suspension system can no longer be regarded as rigid. At this time, the vehicle system is considered as three degrees of freedom and the suspension is considered as flexible system.

(2) Teaching on selection of model coordinate system

In the textbook, the dynamic coordinate system consolidated on the car is used to describe the model. At the same time, it is pointed out that the mass distribution parameters, such as the moment of inertia, are constant for the dynamic coordinate system consolidated on the vehicle, which is the convenience of using the vehicle coordinate system. As long as the absolute acceleration and angular acceleration of the vehicle and the external forces and moments are decomposed along the axes of the vehicle coordinate system, the differential equations of motion along these axes can be listed.

After explaining the advantages, teachers need to guide students to use dialectical thinking to view these advantages, which are not absolute. Relativity and absoluteness are dialectical transformations. When analyzing the trajectory of a vehicle, it is inconvenient to adopt the dynamic coordinate system consolidated on the vehicle, but the coordinate system consolidated on the ground should be adopted. It is easier and more convenient to describe the movement of a vehicle when it travels on a straight road at a constant speed. In view of the selection of coordinate system, teachers should guide students to think deeply after class, establish a fixed ground coordinate system, re-study the dynamics model, and compare the similarities and differences between the two coordinate systems. Besides, teachers should remind students that things are generally connected and transformed, and guide students to study how to realize the transformation between the two coordinates.

(3) Teaching of dynamic equations and responses

Traditionally, the teaching of vehicle handling and stability is limited to theoretical analysis and students lack intuitive understanding. If the multi-body dynamics simulation software such as Adams is used for the simulation analysis, students can deepen their understanding of the principle through the phenomenon of motion. This teaching method combines theoretical analysis with the simulation experiment, effectively avoids the above shortcomings, and further enriches the teaching content. Among them, the expression of vibration response is deduced by theoretical analysis, dynamic response program and simulation test program are compiled by using MATLAB software, data processing and vibration response analysis are carried out, and dynamic simulation is conducted by using Adams software to intuitively observe the movement of vehicles.

In explaining the dynamic equations and responses, we should pay attention to the following two points:

Based on the basic model of vehicle handling and stability, students can easily grasp the basic characteristics of vehicle handling and stability, and expand it to a complex model, which lays a good foundation for students' follow-up work and scientific research.

Applying the principle of the relationship between the phenomena and the essence, combining theoretical analysis and simulation experiment, teachers can improve the quality of teaching.

(4) Analysis of teaching effect

"Vehicle handling and stability" is the core chapter of the core course of vehicle engineering and other related specialties. The degree of students' mastery is directly related to their understanding of vehicle performance. Through the flexible use of philosophical thinking, this teaching method makes in-depth explanation and analysis of vehicle handling dynamics model and the response analysis. Through the virtual simulation experiment of the vehicle handling stability, students can understand the main vehicle handling characteristics and the basic vehicle handling dynamics model and its modeling methods. Students can easily master the evaluation methods and evaluation indicators of vehicle handling stability, and deepen the vehicle handling. This can help to improve students' innovative ability.

After the use of this teaching method in Shandong University of Technology, students generally respond well and their enthusiasm for learning is obviously strengthened.

\subsection{Promotion and Application Measures}

(1) Continuous construction and renewal

Colleges and universities should strengthen the consciousness of philosophical thinking, continuously promote the innovation of teaching platform, promote the application of modern information and simulation technology in teaching, share teaching resources, comprehensively improve the quality of teaching, so as to enhance the innovative ability of students.

(2) Teaching promotion and application program for colleges and universities

Relying on the existing teaching team, colleges and universities should give full play to the exemplary role of excellent courses based on the cultivation of innovative ability of philosophical thinking. Facing the popularization and application of universities, the demonstration and leading role of virtual simulation experimental teaching platform is brought into play and expanded.

\section{(3) Social-oriented and sustainable service program}

On the premise of ensuring the completion of relevant teaching tasks, colleges and universities should constantly improve the teaching platform, intensify social development efforts. In addition, colleges and universities should give full play to the functions of the platform, actively provide open 
services to the society, and maximize the utilization of teaching resources.

\section{Conclusions}

To effectively enhance undergraduates' innovative ability, this paper proposed a method of integrating philosophical thinking into professional courses teaching. After the use of this method in Shandong University of Technology, undergraduates generally respond well and their enthusiasm for learning is obviously strengthened. Through the study of philosophical thinking and college students' innovative ability and the analysis of teaching reform suggestions and case study, it can be seen that:

Philosophical thinking is the necessary condition of the innovative ability. The innovation ability is the actual end-result of philosophical thinking. Philosophical thinking and innovative ability are dialectically unified.

Combining philosophical thinking with professional teaching can cultivate undergraduates' ability to apply philosophical methodology and effectively improve their innovative ability.

Colleges and universities should actively promote the teaching method of combining philosophical thinking with professional course teaching, and give full play to the exemplary role of excellent courses based on this teaching method.

It is suggested to further strengthen the integration of philosophy and curriculum teaching.

\section{Acknowledgements}

This work was supported by the Scientific Research Foundation for Doctors (419067).

\section{References}

[1] ZHANG Guo-hua. (2016). New Ways of Students' Innovative Entrepreneurship Education in Universities. Education Teaching Forum, 48 (11): 221-222.

[2] YU Wen-xiang. (2016). Research on the College Innovative Education and innovative Quality. Journal of Tianjin Vocational Institutes, 18 (2): 37-40.

[3] CHANG Cheng-xia. (2018) Research on the Integration of
Quality Education and Innovation and Entrepreneurship Education in Universities of Science and Engineering in China. Teacher Education and Curriculum Studies, 3 (1): 6-9.

[4] ZHOU Chang-cheng and REN Chuang-bo. 2008. Innovative Maths-Thinking and Study on Ability Cultivation of Graduate Students. Research in Higher Education of Engineering, Supplement, 26-28.

[5] XU Wei-ping. (2016). Research on the Education of Entrepreneurship and Innovation in China: from the Prospective of Document Analysis. Journal of Changzhou Vocational College of Information Technology, 15 (2): 88-95.

[6] ZHAO Xiang-jun \& ZHOU Ying. (2016). On College Students' Quality Education. Journal of Heilongiiang College of Education, 35 (5): 10-12.

[7] ZHOU Jian-song \& ZOU Hong-qiu. (2015). Responsibility and Strategies of the Quality Education in Universities. Research in Higher Education of Engineering, 6 (1): 125-129.

[8] ZHANG Qi-xiang. (2017). On China's New Entrepreneurship Education Frame with the Policy Backgrounds of Popular Entrepreneurship and Innovation. Journal of Jilin Teachers Institute of Engineering and Technology, 38 (3): 140-146.

[9] ZHOU Chang-cheng and LIU Yuan-yi. (2008). Study on Major Basic courses and Innovative Ability Cultivation of Engineering Students. Research in Higher Education of Engineering, Supplement, 1-3.

[10] Seung Hwan Shim. (2008) A philosophical investigation of the role of teachers: A synthesis of Plato, Confucius, Buber, and Freire. Teaching and Teacher Education, 24 (3): 515-535.

[11] CHRISTIE Michael. (2017) The philosophical and pedagogical underpinnings of Active Learning in Engineering Education. European Journal of Engineering Education, 42 (1): 5-16.

[12] ZHANG Meng. (2014) Philosophy and the modern courses education using grey system theory. Energy Education Science and Technology Part A: Energy Science and Research, 32 (6): 7725-7728.

[13] BORONDO, J. (2014) Adapting physics courses in an engineering school to the b-learning philosophy. European Journal of Engineering Education, 39 (5): 496-506.

[14] KASHI Anirudh. (2017) A Score Recommendation System Towards Automating Assessment In Professional Courses. roceedings - IEEE 8th International Conference on Technology for Education, T4E 2016, 140-143.

[15] YU, Zhi-sheng. (2009) Automobile theory, Machinery Industry Press: Beijing. 